\title{
HIV/TB co-infection and availability of health services in relation to socio-economic status
}

\author{
Bhim Bahadur Subba ${ }^{1}$ and Nirmal Rimal \\ ${ }^{1} \mathrm{PhD}$ Scholar, Mewar University, Rajasthan, India, ncdcvim@yahoo.com
}

\begin{abstract}
The human immunodeficiency virus (HIV) pandemic disproportionate affects especially less developed countries and underprivileged communities. HIV weakens immune system of infected individuals and making them more susceptible to tuberculosis (TB) infection. Both HIV and TB disease are supposed to fuel each other socially and biologically and it is further fuelled by such as poor accessibility to services, illiteracy, stigma and discrimination all these factors have pushed Nepal into more vulnerability. This article aimed to find out the availability and accessibility to the HIV/TB services in relation to socio-economic status of respondents. A cross sectional study was conducted at four HIV care and prevention centers of different nongovernmental organizations (NGOs) of Nepal. In the study, 51 samples were selected using random sampling procedures who gave consent to the interview. A pre-tested semi-structured questionnaire was used to collect data. Confidentiality was highly maintained and data were analyzed. The result showed mean age of respondents' was 36.38 years. The pre-dominant 96.1 percent of respondents were from 18-54 years of age. Respondents from all socio-economic status almost two-third indented to use government hospital than private HIV/TB services. The majority 98.0 percent of HIV infected respondents belonged to destitute to better off economic status and they were further disadvantaged by lack of knowledge and information of HIV/TB services such cluster of differentiation 4 (CD4) and viral load service.
\end{abstract}

\section{KEYWORDS}

Access to services, HIV/TB co-infection, Socio-economic status

\section{INTRODUCTION}

Since the discovery of Human Immune-deficiency Virus (HIV) in 1981, the HIV pandemic disproportionate affects especially less developed countries and underprivileged communities and killed about 1.2 million people in 2014. (UNAIDS, 2015). The emergence of HIV epidemic is contributing definitely to upward trend of Tuberculosis (TB) morbidity and mortality 
(Dhungana, 2012). HIV weakens of immune system of infected individuals and making them more susceptible TB infection. It is well-known that a HIV infected with latent TB infection has a 10 percent chance of progressing to active TB each year in contrast to HIV negative. (WHO, 2006). Therefore, HIV increases the risk of contracting TB in HIV infected person and diseases fuel each other socially and biologically (Subedhi, 2003).

The association between HIV and TB are great public health problem and socio-economic threat in developing countries. In Nepal, there is well known relationship between HIV and TB among the adult population (15-49 age) and estimated prevalence at range 0.20-0.3 percent (NCASC, 2015). The most of HIV new infections were largely driven by sexual transmission, accounting more than 85 percent of the total in the country (NCASC,UNAIDS, 2013). Therefore, the HIV/TB co-infection is coming up one of greatest challenges among the young and productive age group which will have serious impacts in the socio-economic life (Subedhi, 2003). Many of Nepalese HIV/TB individuals struggle with many social problems such as stigma, poverty, depression, and cultural belief that affect quality of life and assessing health care services of individuals. (Timilsina \& Regmi, 2014).

The existing socio-economic status, prevailing norms and values, cultural myths on sex and sexuality and a huge population of marginalized communities make it also extremely vulnerable to the HIV epidemic in Nepal (Dhungana, 2014). The spread of HIV is further fuelled by poor accessibility to services, illiteracy, stigma and discrimination. All these factors have pushed Nepal into more vulnerability. Therefore, government of Nepal identified various population sub-groups as "high risk behavior groups" (Suvedi, 2006) and this study also focused their problems in accessing to available HIV/TB services as being PLHIV. The study highlights the respondents' access to Counter Differentiation (CD4) testing and early initiation of Antiretroviral Therapy (ART) and Direct Observed Treatment Short Course (DOTS) therapy reduces mortality among People living with HIV (PLHIV).

\section{MATERIALS AND METHODS}

A cross-section pilot study was conducted at four HIV care and prevention centers such as National Community Development Center (NCDC) Morang, Happy Nepal Jhapa, Kirat Yakthung Chumlunng (KYC) Punarjivan centre Sunsari, Nava Jivan Sewa Samaj(NJSS), Sunsari of different Non-Government Organizations (NGOs) of Nepal, from December 2013 to 
September 2014. The respondents who were on ART or TB treatment or only HIV infected individuals were enrolled in the study. The inform consent of respondents and ethical approval from Nepal Health Research Council (NHRC) were obtained before starting the study. Over a six month period, such 51 HIV/TB co-infected individuals over 18-65 years of age were included in the study. Respondents visiting Volunteer Confidential Counseling Testing (VCCT), Prevention Mother to Child Transmission of HIV (PMTCT) and admitted in the hospitals were excluded for their confidential matters. A pretested semi-structured questionnaire was prepared in both Nepali and English language and data were collected through face to face interview by trained research personnel. The collected data were verified and correlated with their diagnosis report of individuals. Following socio-economic variables such age, sex, education attainment, residence, monthly income, employment status were included in the questionnaires. Confidentiality was highly ensured to the respondents. All data were coded, edited, cleaned and anonymized before entry of data and data were analyzed using Statistical Package for the Social Sciences (SPSS 20) version; in terms of mean and percentages in cross tabulation.

\section{RESULTS}

Table 1: Socio-economic characteristics of respondents.

$\mathbf{N}=\mathbf{5 1}$

\begin{tabular}{|llccc|}
\hline \multirow{2}{*}{ Characteristics } & & \multicolumn{2}{c}{ Co-infection status (\%) } & \\
\cline { 3 - 4 } & & HIV & HIV/TB & Total \\
\hline \multirow{2}{*}{ Age } & Below 45 & 97.2 & 93.3 & 96.1 \\
Mean age 36.38 years & & 2.8 & 6.7 & 3.9 \\
\hline \multirow{3}{*}{ Gender } & Female & 38.9 & 60.0 & 45.1 \\
& Male & 61.1 & 33.3 & 52.9 \\
\hline \multirow{3}{*}{ Education } & Transgender & 0.0 & 6.7 & 2.0 \\
& Illiterate & 30.6 & 40.0 & 33.4 \\
\multirow{2}{*}{ Residence } & Primary & 55.6 & 46.7 & 52.9 \\
& Secondary & 13.7 & 13.3 & 13.7 \\
\hline \multirow{3}{*}{ Occupation } & Rural & 30.6 & 29.4 & 51.0 \\
& Urban & 69.4 & 0.0 & 49.0 \\
\hline Monthly income of & Employed & 25.0 & 13.3 & 21.5 \\
family (NRs) & Self-employed & 22.2 & 53.3 & 31.4 \\
& Unemployed & 152.8 & 33.3 & 47.1 \\
\hline & 7000-14999 & 19.4 & 20.0 & 19.6 \\
& & 61.1 & 73.3 & 64.7
\end{tabular}




\begin{tabular}{|c|c|c|c|c|}
\hline & \multicolumn{3}{|c|}{ Mean monthly income (NRs) 9647.05} & 15.7 \\
\hline \multirow{3}{*}{ Economic status } & Destitute & 27.8 & 40.0 & 31.4 \\
\hline & Better off & 72.2 & 53.3 & 66.6 \\
\hline & Best off & 0.0 & 6.7 & 2.0 \\
\hline
\end{tabular}

Source: Field survey, 2015

Table 1 presents socio-economic characteristics of the sample respondents of HIV/TB coinfected. Of total, the majority of respondents was young and productive age group and found with high HIV prevalence. Men had a greater burden (52.9 percent were males and 45.1 percent females) of HIV/AIDS than women among study respondents. The most of respondents belonged to age ranged between 18-60 years with a mean age 36.38 years. The predominant 96.1 percent of respondents were from 18-45 years of age and more than 93.3 percent of respondents found HIV/TB co-infection. In term of education, the largest segment 52.9 percent of respondents had got primary level education and only few 13.7 percent respondents received secondary level education and above. Analysis of wealth status of respondents showed that the majority 66.6 percent HIV/TB co-infected belonged to better off, followed by few 2.0 percent of respondents belonged to best off and with a monthly average per capita income of less than NRs.9647.05. The majority 51.0 percent of HIV/TB co-infected respondents lived in urban area compared to urban residence.

Table 2: HIV/TB co-infection and access to service in relation to employment status of respondents.

\begin{tabular}{|lccccc|}
\hline \multicolumn{2}{|c}{ Access to service } & \multicolumn{3}{c}{ Employment status (\%) } & N=51 \\
\cline { 2 - 5 } & & Employed & Self-employed & Unemployed & Total \\
\hline \multirow{2}{*}{ NGO service } & Yes & 7.8 & 43.1 & 47.1 & 98.0 \\
& No & 2.0 & 0.0 & 0.0 & 2.0 \\
\hline \multirow{2}{*}{ VCCT service } & Yes & 9.8 & 39.2 & 39.2 & 88.2 \\
& No & 0.0 & 3.9 & 7.8 & 11.8 \\
\hline \multirow{2}{*}{ Viral load service } & Yes & 2.0 & 2.0 & 11.8 & 15.7 \\
& No & 7.8 & 41.2 & 35.3 & 84.3 \\
\hline \multirow{2}{*}{ CD4 service } & Yes & 9.8 & 29.4 & 35.3 & 74.5 \\
& No & 0.0 & 13.7 & 11.8 & 25.5 \\
\hline \multirow{2}{*}{ ART service } & Yes & 7.8 & 31.4 & 41.2 & 80.4 \\
\cline { 1 - 4 } DOTS service & No & 2.0 & 11.8 & 5.9 & 19.6 \\
\hline
\end{tabular}




\begin{tabular}{|ccccc|} 
No & 7.8 & 25.5 & 37.3 & 70.6 \\
\hline
\end{tabular}

Source: Field survey, 2015

Table 2 describes the frequency with which respondents used to access different types HIV/TB services according to their employment status. Most of all income categories about 98.0 percent respondents reported they accessed to NGOs run HIV/TB services due to motivation and mobilization of peer groups. Therefore, more than three-quarter 88.2 percent respondents accessed VCCT, and in contrast to 11.8 percent respondents did not access VCCT service at the time of survey. In addition to this, about 84.3 percent respondents did not access viral load service and three quarter 75.0 percent unemployed respondents reported that they accessed regular CD4 services. The analysis of result revealed that 80.4 percent respondents were on ART in the hope of receiving free of cost services. All 29.4 percent HIV/TB co-infected individual access DOTS service after the diagnosis of TB.

Table 3: Socio-economic status and health care utilization by respondents.

\begin{tabular}{|llcccc|}
\hline Characteristics & & \multicolumn{2}{c}{} & N=51 \\
\cline { 3 - 5 } & & Prefer to go to take services (\%) & Total \\
\cline { 2 - 5 } Economic status & Government & Private & NGO & \\
& Destitute & 29.4 & 2.0 & 0.0 & 31.4 \\
& Better off & 52.9 & 7.8 & 5.9 & 66.7 \\
& Best off & 2.0 & 0.0 & 0.0 & 2.0 \\
\hline Employment & Employed & 17.6 & 3.9 & 0.0 & 21.6 \\
status & Self-employed & 27.5 & 2.0 & 2.0 & 31.4 \\
& Unemployed & 39.2 & 3.9 & 3.9 & 47.1 \\
\hline Monthly income & Below 6999 & 19.6 & 0.0 & 0.0 & 19.6 \\
(NRs) & $7000-14999$ & 52.9 & 5.9 & 5.9 & 64.7 \\
& 15000 Above & 11.8 & 3.9 & 0.0 & 15.7 \\
\hline
\end{tabular}

Source: Field survey, 2015

Table 3 describes the frequency of respondents' utilized different types of health care services according to their socio-economic status. Of total, more than majority 52.9 percent better off respondents indented to use government hospital to take HIV/TB services. In case of unemployed; more than one-third 39.2 percent respondents used government hospital services compared to others employment categories. Similarly, the majority 52.9 percent respondents having NRs. 7000.0-14999.0 monthly income group used to access government services than other two income groups. Among the monthly income categories, the trend of use of private 
hospital services was almost high and more than 3.9 percent respondents used to access private hospital as their health need. In conclusion, the trends of using government hospital services were found high in middle-income categories compared to other low and high income categories.

\section{DISCUSSION}

In recent years, the alliance of HIV/TB co-infection threats great concern of tuberculosis control, especially in developing countries. Over the years, low socio-economic status has been closely linked to increased risk of developing HIV/TB co-infection in Nepal and over 11.5 percent patients suffering from HIV/TB and most of them died before access the services (NTC, 2012). This study also investigated the relationship between most commonly used HIV/TB services and in relation with socio-economic characteristics of respondents (namely education attainment, employment status and monthly income). The study revealed that majority 96.1 percent respondents of age below 45 were PLHIV and most of them were unemployed. This finding is similar to what obtains globally that tuberculosis affects the low socio-economic status (Khatri and Frieden, 2000).

The findings of the study showed, HIV prevalence was found high among the economically better off respondents and specifically among men than women. The respondents reported that the better off family with urban residence felt more vulnerable to HIV/TB co-infection compared to those respondents from destitute family. In particular, the study also pointed out the problems that the destitute and better off respondents from rural and urban residence faced dual challenges like vulnerability infection and lack of information on HIV/TB services and access it. Magadi conducted one study and found that the urban poor were noted to have significantly higher odds of HIV infection than their urban non-poor counterparts (Magadi, 2013). The study revealed that the respondents with low socio-economic characteristics having low level educational attainment were more vulnerable to HIV/TB co-infection compared to those in high socio-economic group. This study results are consistent with Wabiri and Taffa study findings the bidirectional relationship between socio-economic inequality and poor health results (Wabiri \& Taffa, 2013). Viswanath (2006) indicated that those in low Socio-Economic Status (SES) also tended to gain less form of information flows than their counterparts of higher SES and felt inequalities in HIV/AIDS service delivery. 
In this study the majority 52.9 percent of employed and self-employed respondents were HIV/TB co-infected. It is obvious those employed might have accessed more information and tended to expose with risky behavior than others. Our findings revealed the most of HIV/TB prevalence belonged to those respondents having extramarital sexual exposure and early involvement of high risk behaviours. In case of socio-economic status that better off respondents had found high prevalence of HIV/AIDS than other counterparts of society. The concentration and variation of HIV/AIDS among men and women may be explained by behavioural differences (Msisha et al., 2008). We also found that the unsafe sexual practices with their migrant husband were one of the causes of high prevalence of HIV/AIDS among female in the study area. Walque described the higher prevalence of HIV/AIDS among middle class individuals and high socially advantaged individuals are more likely to access HIV/TB services and have found long survival relative to poorer individuals (Walque, 2006).

In terms of education, our study revealed that the older adults with higher education profile adopted some protective measures against HIV and found low HIV prevalence. The results showed that respondents those with non-formal and primary education had more likely to be HIV positive than older adults with secondary education background and more. The older adults with having primary education and more had 52.9 percent HIV prevalence compared to less than secondary level education with 13.7 percent HIV prevalence. These findings were about similar to others study that anybody who is illiterate and educated below the secondary education may not have sufficient knowledge to protect themselves from HIV/AIDS. (Joge, et al., 2012)

In addition, this study also examined the significant relationship with type of residence of respondents that may affect $\mathrm{HIV} / \mathrm{TB}$ co-infection and access to services. More than 51 percent both male and female respondents from urban residence had higher HIV prevalence compared to those from urban ones. It seems urban populations are working as buffering /bridging for HIV infection from urban to rural population. Similar findings were reported by Joardar and Sarkar, 2006. A study carried out from Jammu and Kasmir showed that there was high prevalence of HIV in rural areas than urban (Soyam et al., 2016).

\section{CONCLUSIONS}

There was relatively high prevalence of HIV/TB co-infection among better off and destitute family in the study area. The poor and productive age groups were further disadvantaged by lack 
of access to HIV information and HIV services such CD4 and viral load service. Stakeholders should consider socio-economic characteristics of PLHIV as they formulate intervention to improve to access HIV/TB services. It is more imperative that physician and ART provider should aggressively send individual having CD4 350 below for TB prophylaxis. There is high urgency to reduce the TB mortality focus on particularly for poor PLHIV women.

\section{REFERENCES}

De Walque, D. (2006). Who Gets AIDS and How? The Determinants of HIV Infection and Sexual Behaviors in Burkina Faso,Cameroon, Ghana, Kenya, and Tanzania.

Dhungana, G. \&. (2014). Tuberculosis tatus among patients visiting antiretroviral therapy centers of Seti Zonal Hospital and Mahakali Zonal Hospital of far western Nepal. Journal of Advances in Internal Medicine, 3(5), 11.

Fox, A. (2012). The HIV-poverty thesis re-examined: poverty, wealth or inequality as a social determinant of HIV infection in sub-Saharan Africa? Journal of Biosocial Science(44), 459480 .

Joardar G.K. Sarkar A, C. C. (2006). Profiles of Attendees in the VCTC of North Bengal Medical College in Darjeeling of West Bengal. Indian Journal of Community Medicine, 3(4), 239-240.

Joge, U. S., Deo, D. S., Lakde, R. N., Choudari, S. G., Malakar, V. R., \& Ughde, H. (2012). Sociodemographic and clinical profile of HIV/AIDS patients visiting to ART Centre at a rural tertiary care hospital in Maharashtra state of India. International Journal of Biological \& Medical Research, 1568-1572.

Magadi, M. (2013). The disproportionate high risk of HIV infection among the urban poor in sub-Saharan Africa. AIDS Behaviour, 17, 1645-1654.

Marahatta, S. (2012). Knowledge on HIV/AIDS Among the bus driver of Dhulikhel,Nepal. IX(1). Retrieved 2015

Msisha, W., Kapiga, S., Earls, F., \& Subramanian, S. (2008). Socioeconomic status and HIV seroprevalence in Tanzania: a counterintuitive relationship. International Jounal Epidemiology(37), 1297-1303.

NCASC. (2006). National HIV/AIDS Strategy(2006-2011). Kathmandu: National Control for AIDS and STD control.

NCASC. (2010). National Estimate of HIV Infections 2009. Kathmandu: Nationa Control for AIDS and STD Control. 
NCASC. (2015). Country progress report Nepal. Kathmandu: National Centre for AIDS and STD Control.

NCASC,UNAIDS. (2013). The Nepal HIV Investment Plan 2014-2016. Kathmandu: National Centre for AIDS and STD Control.

Ogunmola, O., Olatunji, O., \& Olamoyegun, M. (2014). Relationship between socioeconomic status and HIV infection in a rural tertiary health center. HIV/AIDS - Research and Palliative Care, 61-68.

Singh, H., Singh, G., \& Singhl, T. (2007). Esitimiation of CD+4 and CD+8 lymphocytes in HIV infection and AIDS patients in Minipur. Indial Journal of Medical Microbiology, 25(2), 12632.

Soyam, V. C., Das, J., Rajeeva, T., Baro, P., \& Kohli, C. (2016). Prevalence and sociodemographic correlates of HIV Aiamong Tuberculosis patients of DOTS centre in Delhi. Asian Journal of Medical Sciences, 7(1), 53-59.

Steinberg, M., Johnson, S., Schierhout, G., \& Ndegwa, D. (2002). Hitting home: how households cope with the impact of the HIV/AIDS epidemic: a survey of households affected by HIV/AIDS in South Africa. Washington, DC: Henry J. Kaiser Family Foundation.

Subedhi, B. (2003). HI-TB co-infection in Nepal. Journal of the institute of medicine, 21. Retrieved 9 15, 2014

Subedi, B. (2006). The far western region of Nepal has a relatively high burden. Kathmandu university medical journal, 4(8), 115.

Suvedi, B. (2006). Transition of HIV epidemic in Nepal. Kathmandu university medical journal, 4(13), 115-118.

Temah Tsafack, C. (2008). Socio-Economic Inequalities and HIV/AIDS Epidemic:Evidence from Sub-Saharan Africa. Doctoral dissertation, Doctoral dissertation. France:: University d'Auvergne, Clermont-Ferrand.

Timilsina, S., \& Regmi, K. (2014). Assessing quality of life and depression among people living with HIv/AIDS and TB-HIV co-infection in Kathmndu , Nepal.

Tiwari, B. (2008). Immune status of HIV patients in Nepal. Institute of science and technology, Central department of Microbiology. Kathmandu: Tribhuvan University.

UNAIDS. (2004). Epidemiological fact sheets on HIV/AIDS and sexually trasmitted infections. UNAIDS, unicef,WHO.

UNAIDS. (2014). Geneva, Switzerland. Retrieved November 01, 2014, from unaids.org 
UNAIDS. (2015). How AIDS changed everything. UNAIDS.

Wabiri, N., \& Taffa, N. (2013). Socio-economic inequality and HIV in South Africa. Pretoria: BMC Public Health. Retrieved 2 05, 2015, from http://www.biomedcentral.com/1471$2458 / 13 / 1037$

WHO. (2006). Stop TB partnership. Geneva: Worl Health Organization.

Zanakis, S., Alvarez.C, \& Li, V. (2007). Socio-economic determinants of HIV/AIDS pandemic and nations efficiencies. European Journal of Operational Research(176 ), 1811-1838. doi:doi:10.1016/j.ejor 